\title{
Learning spaces, agency and notions of improvement: what influences thinking and practices about teaching and learning in higher education? An interpretive meta-ethnography
}

\author{
Maggi Savin-Baden*, Lorraine McFarland and John Savin-Baden \\ Coventry University, UK
}

\begin{abstract}
This review sought to locate key themes in the literature on teaching and learning thinking and practices, by examining areas of influence and mapping ideas about the themes of practice, transfer and communities in higher education or related contexts. The findings indicate that issues of pedagogical stance, disjunction, learning spaces, agency, notions of improvement and communities of interest can help to locate overarching themes and hidden subtexts that are strong influences on areas of practice, transfer and community. Nevertheless, these are areas that are sometimes ignored, marginalised or dislocated from the central arguments about teaching and learning thinking and practices in higher education.
\end{abstract}

Keywords: learning spaces; agency; meta-ethnography; practice; transfer; community

\section{Introduction}

This review focused on the literature relating to teaching and learning thinking and practices. In particular it set out to explore the questions:

- What does the literature indicate about thinking and practices about teaching and learning in higher education?

- What are the tensions and differences across practice and communities?

- What is the relationship between theories of teaching and learning and actual practices?

It examined the nature and extent of engagement with these ideas in literature intended for 'stakeholder' groups: academic teaching staff (practitioners); institutional policy makers; and educational developers. The literature was initially grouped within three initial core themes:

Practice: The idea of practice considered the literature that explored the nature of teaching and learning practices, including those that were tacit and highly situated.

Transfer: Literature that critiqued ideas about transfer, and also examined the possibilities for, and realities of transfer, across both knowledge domains and areas of practice.

Community: Literature that related to an understanding of the communities included literature on: academic identity; networks and communities of practice; knowledge management; and the role and orientations of change agents, including educational development agencies and practitioners.

\section{Background}

The continuing debates about the nature and process of learning and teaching in higher education have created a minefield of overlapping concepts, with few clear frameworks for

*Corresponding author. Email: m.savinbaden@coventry.ac.uk 
understanding the relationship across practice, transfer and community. Traditionally, learning theories have been grouped into categories, from the behavioural traditions through to the critical awareness theorists, but with full acknowledgment that one may overlap with another. A strand that appears to have received relatively little attention, in the area of ways of thinking and practice of higher education, is that of the critical awareness tradition. Those in the field of critical awareness have argued that theirs is not simply another perspective on adult learning, but rather a shift in ideology. The ideals of this tradition stem largely from theorists such as Freire (1972, 1974), who argued that social and historical forces shape the processes through which people come to know themselves and develop their view of the world. Learning is therefore seen to occur in a social and cultural context and this necessarily influences what and how people learn. Learners therefore must seek to transcend the constraints their world places upon them in order to liberate themselves and become critically aware. More recently the work of hooks (1994) has helped to further this work, and to some extent Pratt et al. (1998), but it remains a tradition that has gained relatively little attention, although it may soon do so with the onset of the Web 2.0 movement, the increasing shift toward learning as social networking and the interest in Bauman's work on liquidity (Bauman 2000).

However, it could be argued that a theorist such as Barnett (1997, 1990, 1994, 2000a, 200b) has straddled both a cognitive tradition and a critical awareness tradition through the way in which he has theorised the position of higher education over the last 20 years. Barnett argued that curricula may be either 'inward-looking, reflecting a project of introjection where they are largely the outcome of academic influence', or 'outward looking, reflecting a project of projection, where they are subject to external influences' (Barnett 2000b, 263-4). Barnett predicts that at the macro-level (state and institutional policy) change will be in the direction of projection and from insulated singulars towards increasingly multidisciplinary or interdisciplinary regions. Yet despite the multiple claims from outside academe, he suggests that 'the discipline (or knowledge field) constitutes the largest claim on the identity of academics' (264), and consequently the micro-level of actual curricular changes will reflect both the extent to which disciplines within institutions are yielding their insularity, and the changes within disciplinary fields of inquiry. Change, then, will largely depend upon the relative strength of institutions against that of their constituent disciplines, and the positioning of individual institutions within the higher education system. What is interesting about this argument is Barnett's belief that disciplinary identities will necessarily prevail over performativity where institutions are powerfully positioned in the national hierarchy of universities. Although the work of Becher (1989) and more recently Becher and Trowler (200I) has raised awareness of possible disciplinary difference, research into teacher knowledge is relatively new to higher education. Teacher knowledge and beliefs about what to do, how to do it, and under which circumstances can affect the way that students learn particular subject matter.

In the UK there has been increasing discussion about discipline-based pedagogy. Jenkins and Zetter (2003) argue that disciplines shape the nature of pedagogy and such pedagogies reflect the practices and culture of the discipline. However, what is not clear in the studies and discussions about discipline-based pedagogy is how it is that faculty break down disciplinary restrictions and instead search for more interdisciplinary approaches. Recently, studies into disciplinary difference have been explored by Meyer and Land (2003), who argue for the notion of 'threshold concepts'; the idea of a portal that opens up a way of thinking that was previously inaccessible. Although initially Meyer and Land argued for such a concept being located as something distinct within a set of core material that university lecturers would teach, more recently (Meyer and Land 2004) they have broadened this to include wider concepts such as staff experiences. This work is gaining increasing acclaim, possibly because of the resonance it has with many staff about why it is that students become 'stuck' in learning. 
Thus, amidst this broad canvas of traditions, philosophy and research, this review used interpretive meta-ethnography to explore what the literature since the 1990s has indicated about the extent to which learning theories have in fact influenced ways of thinking and practising about higher education. The focus of this review was thus to:

- identify the key literature that problematised and clarified the ways in which practice, transfer and communities may be viewed;

- explore the ways in which practitioner, policy and development literature understands and uses these key terms, noting that these are not entirely discrete categories of literature;

- examine the tensions among these audiences, in relation to differing conceptions and practices;

- explore areas in which available knowledge is not used to inform thinking and practices;

- locate areas requiring further research to provide evidence that supports or challenges current practices.

\section{Methodology}

This review used interpretive meta-ethnography. This is a qualitative approach to managing a large range of literature from the interpretivist tradition in a way that presents an analysis of the findings of data across studies and then interprets it in relation to further themes that emerge across studies. Interpretive meta-ethnography is a systematic approach that enables comparison, analysis and interpretations to be made that can inform theorising and practice. Noblit and Hare (1988) were early developers of this approach who suggested that through interpretation and by acknowledging the researchers as interpretivists, it would be possible to recover the social and theoretical context of research and thus reveal further noteworthy findings. In practice interpretive meta-ethnography involves developing inclusion and exclusion criteria, applying these to studies, and then utilising a three-stage process, developed by Savin-Baden and Major (2007), for managing, analysing and interpreting the selected studies. What is important about interpretive meta-ethnography is that it allows researchers to:

(I) Collate qualitative studies across a large area of literature.

(2) Examine the methodology and findings of each study in depth.

(3) Compare and analyse data and findings for each study.

(4) Undertake an interpretation of data across the studies.

(5) Develop a narrative that emerges from the interpretations.

(6) Provide an overarching interpretation of the central themes that emerge across studies.

(7) Present an interpretive narrative about the findings across studies.

(8) Provide a series of recommendations that relate to an interpretive narrative about the findings across studies.

Although meta-analysis (the process of combining the result of several studies that address a set of related research hypotheses) has developed considerably in medicine and health research, it remains rare amongst educational researchers and developers. Furthermore, meta-analysis remains rare among those using collaborative and interpretative inquiry, and few researchers have undertaken an integration of findings from these kinds of studies. Those who have undertaken such a task have tended either to impose the frameworks and values of quantitative systematic reviews on qualitative studies or have moved towards the use of metasynthesis. The use of systematic reviews, of whatever sort, implies that the drawing up of a set of rules for 'systematically' reviewing evidence will necessarily make the process of the review and research transparent. Yet there are degrees of transparency and points beyond which it is 
not possible to go when undertaking such reviews. The difficulty with meta-analysis that is not located in an interpretive tradition is the propensity to decontextualise material, thin descriptions, and ignore methodological difference. Meta-ethnography was undertaken for this study at three levels described in Figure I.

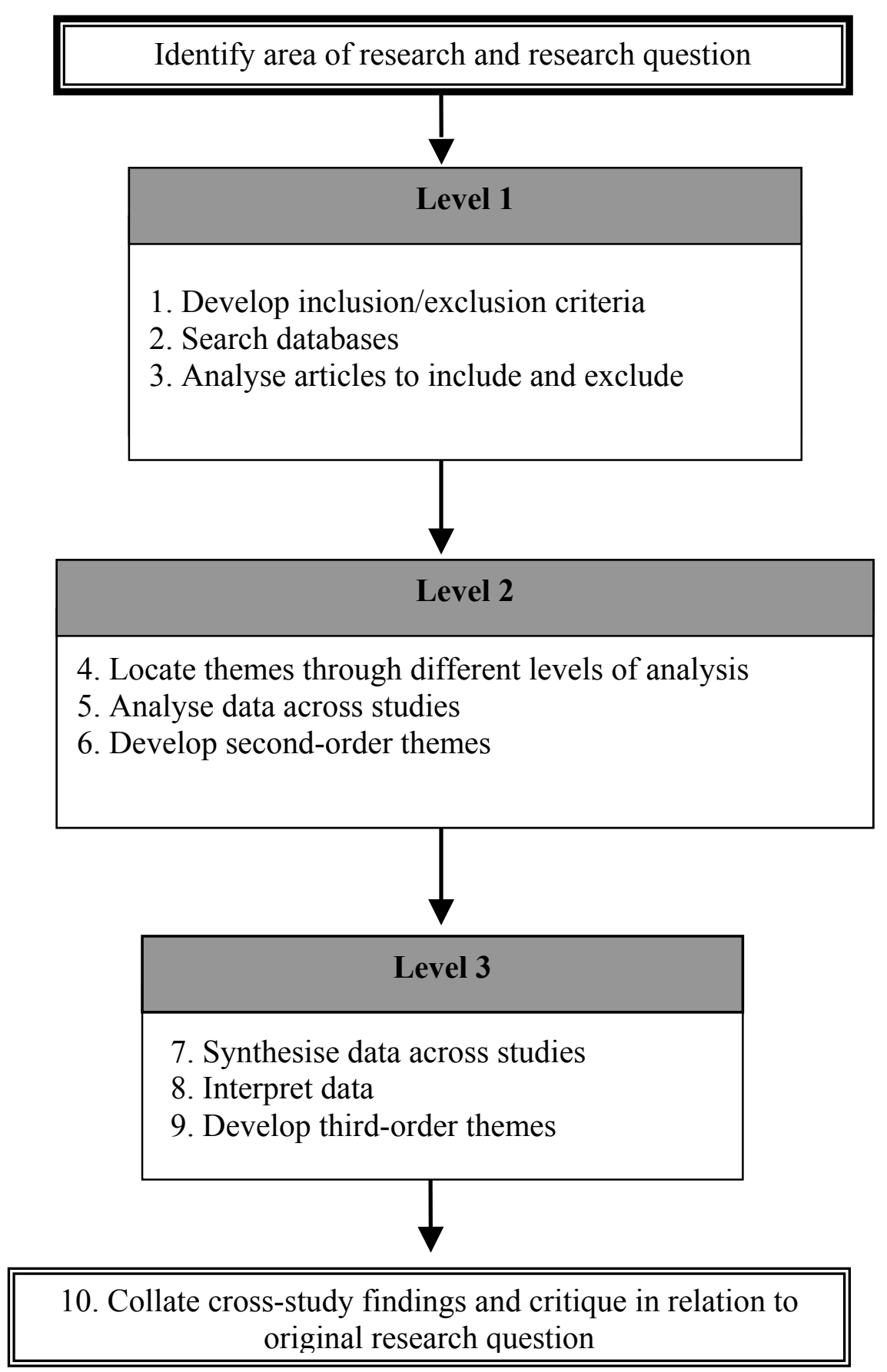

Figure I. Stages of interpretive meta-ethnography. 


\section{Identification, selection and analysis of the literature}

This literature review used meta-ethnography of each theme at three levels: Level I, searching and analysing articles to include and exclude; Level 2, locating articles in relation to core themes and sub-themes through different levels of analysis; and Level 3, synthesising data. At Level I, in addition to standard searching methods, several other approaches were used to identify potential studies, including scanning bibliographies of original and review articles for other suitable studies, hand-searching, reviewing listservs and other relevant mailing lists, and searching the Cochrane networks. The Cochrane Collaboration is a group of over II,500 volunteers in more than 90 countries who apply a rigorous, systematic process to review the effects of interventions tested in biomedical randomized controlled trials, non-randomized, and observational studies. The results of these systematic reviews are published in the Cochrane Library. The initial search yielded over 6000 articles, edited collections and monographs. Inclusion and exclusion criteria were developed (Table I) along with key search terms. However, by including the term 'qualitative research', the results were reduced to more manageable proportions. The search terms 'teaching and learning theory' and 'knowledge development' presented overlapping research papers. Of the final 150 articles located from all sources, 47 were rejected, mainly for using mixed methodologies although this was not apparent from the abstract. However, on reading the whole articles, a further 20 were excluded due to the use of mixed methods or the quantitative operationalisation of qualitative research findings.

At Level 2, annotations, maps, tables and grids were used to identify and connect studies with the key themes. For example the mapping of methods, concepts and findings was undertaken, as presented in Table 2, in order to illustrate how analysis moved beyond mere summary.

Data were analysed by interpretative comparison and inductive analysis. Rather than just starting with raw data, some predetermined themes and descriptions that the original authors had chosen to include were used. Indeed, it is unusual in meta-ethnography to reinterpret completely the original data. In practice this meant that not only were data compared across the studies but also metaphors, ideas, concepts and contexts were revisited in order to review how the initial findings had been contextualised and presented. In practice this meant:

(I) Reading the studies carefully and examining the relationship between them to determine common themes.

Table I. Inclusion and exclusion criteria.

\begin{tabular}{|c|c|c|}
\hline Criteria & Included studies & Excluded studies \\
\hline Topic & $\begin{array}{l}\text { Learning and teaching theories } \\
\text { Knowledge management } \\
\text { Educational development } \\
\text { Academic practice } \\
\text { Discipline-based pedagogy } \\
\text { E-pedagogy } \\
\text { Higher education research }\end{array}$ & Training \\
\hline Question & $\begin{array}{l}\text { About way literature informs understandings } \\
\text { of practice, transfer and community }\end{array}$ & Learning spaces design \\
\hline Date & Conducted 1990 or later & Conducted prior to 1990 \\
\hline Design & Using a qualitative design & Using a quantitative design \\
\hline Data & $\begin{array}{l}\text { Relying on interviews, focus groups, online } \\
\text { discussions, observations }\end{array}$ & Quantitative questionnaires, surveys \\
\hline
\end{tabular}


Table 2. Mapping of methods, concepts and findings.

Methods, Perceptions and Concepts Article I Article 2 Article 3 Article 4 Article 5 And so on...

Sample

Setting

Methods

Data collection

Notion of validity

Positioning of researcher

Themes and concepts

(2) Synthesising data and discussing the synthesising in order to gain second-order interpretations.

(3) Developing third-order interpretations and adding interpretations that went beyond the mere comparisons of the findings of all the studies.

Analysis of studies was undertaken in relation to three initial themes: practice, transfer and community, across the three 'stakeholders'. References to our themes were mapped, for each area of literature, using the Table 3 matrix. Data were then analysed to gain second-order interpretations, and then develop third-order interpretations (see Table 4) that synthesised the issues across:

- the studies;

- the initial themes of practice, transfer and community;

- the three areas of practitioner, policy and development communities.

\section{Findings at Level 2}

At Level 2 data were tabulated across the themes that emerged below:

- practice: improving practice, changing practice, the impact of innovation, creation of theory through the exploration of practice, students' experiences, and staff experiences;

- transfer: transfer for shared practice, transfer related to policy.

- community: disciplinary communities, online/e-learning communities, staff and educational development communities and inquiry-based and problem-based learning communities;

\section{Findings of Level 3 synthesis and interpretation}

Data were synthesised to explore in more depth the second-order interpretations and to examine, for example, pedagogical stance, diversity and notions of improvement. Evidence of commonality across articles was selected in order to reconceptualise findings across studies. The third-order categories added something that went beyond the mere comparisons of the findings of all the studies. These third-order interpretations emerged to reveal a subtext that was not apparent in the initial common themes.

\section{Third-order themes}

The findings presented in this section emerged in attempting to answer the question: how are practice, transfer and community viewed in higher education and what are the tensions in 


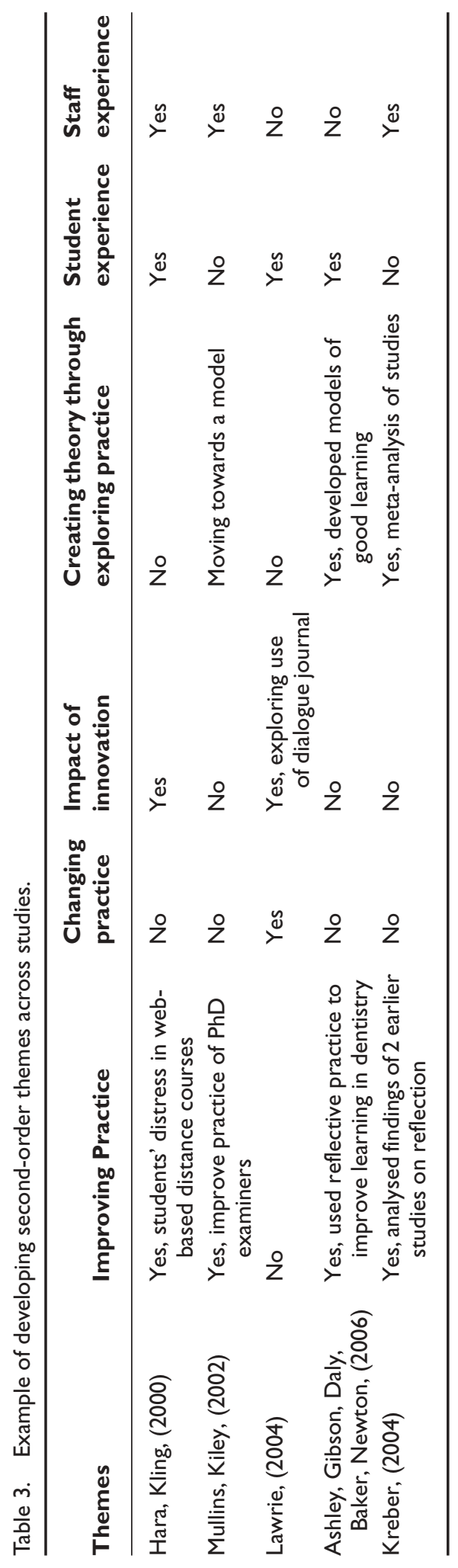


Table 4. Third-order interpretations.

\begin{tabular}{lll}
\hline Initial themes & Second-order interpretations & Third-order interpretations \\
\hline Practice & Improving practice & Pedagogical stance \\
& Changing practice & Disjunction \\
& The impact of major innovation & Learning spaces \\
& Creation of theory & Agency \\
& Student experience & Notions of improvement \\
& Staff experience & Communities of interest \\
Community & Knowledge management & \\
& Disciplinary communities & \\
& Staff and educational development communities & \\
& Academic identity & \\
& Online/e-learning communities & \\
Transfer & Inquiry-based learning communities & \\
& Transfer for shared practice & \\
& Transfer related to policy &
\end{tabular}

relation to differing conceptions and practices? Undertaking third-level synthesis meant that new knowledge was brought to bear on existing material. In practice this meant locating particular issues that related to influencing thinking and practices about teaching and learning in higher education in ways that transcended the areas of practice, transfer and community. These issues shed light on areas that would bear further research and exploration and which in many cases are ones that need to be focused on more frequently by those involved in thinking about teaching and learning.

\section{Pedagogical stance}

On completion of this interpretive ethnography, one of the central overarching issues appeared to be that the impact of the individual pedagogical stance of the academic was a powerful influence in the teaching and learning experience. Pedagogical stance was delineated as the choices and interventions that staff make within a learning environment, and the particular concerns they bring to a learning environment. Tutors' stances emerged from their prior learning experiences, and their often taken-for-granted notions of learning and teaching. The notion of stance encompasses not only conceptions of teaching (Prosser and Trigwell 1999) but also the values implicit in staff perspectives of teaching and learning. For example, Samuelowicz and Bain (200I) suggested staff were either oriented to teaching-centred learning or learning-centred learning. Between them was a 'hard' boundary that was difficult to either cross or temporarily span to 'snatch' a particular approach, method or expertise from the other orientation. Throughout their career, academic staff will be exposed to both orientations through a variety of ways: educational/staff/academic development programmes, other staff from their institution/discipline, at conferences and through the media, or through top-down implementations within their institution. Whether staff stances are teacher or student centred, individualistic or reflective, depends not only on their own values and those of their discipline, but also the forms of academic development programmes they have (or have not) engaged with.

Academic development programmes may not be compulsory across all institutions, and even if compulsory seldom have sanctions against non-completion. Trowler and Cooper (2002) have shown that there was a balance required by staff delivering these programmes, in introducing 'different' concepts of teaching and learning that are oppositional to academics' current 
pedagogical stances. Furthermore, top-down implementation such as teaching or technological innovation could often be avoided, as shown in Souleles $(2005,232)$ in the online/e-learning communities section:

The students use the discussion board ... it is there and if they want to use it they can, but they prefer to ask questions in the tutorials ... I use Blackboard as a facility to inform ... I don't use specific techniques to engage the students ... there is no collaborative process.

Similarly, when teaching innovation was implemented, such as problem-based learning, both Savin-Baden (2000) and Wilkie (2004) described lecturers who had struggled to become facilitators. When teaching-centred orientated academics experience such a learning-centred, top-down implementation, or some might call it imposition, Savin-Baden and Wilkie found entrenched positions starting as non-attendance at facilitator training courses, developing sometimes to attempted sabotage, and ending in a switch to another course, department or even institution. Other less entrenched academics took the line of least resistance, adopting a position of the supplier of all legitimate knowledge and retaining control of both the material and the learning methods. These studies have however shown that, over time, almost all remaining academics embraced the top-down implementation of the innovation, and adopted more learning-centred forms of pedagogy and facilitator roles, thus granting their students an authentic experience of learning-centred learning in the form of problem-based learning.

Sabotage was also described by Pollock and Cornford (2002). They illustrated that despite major institutional backing, once new projects left the close confines of technological development they could stall. In this case, library staff could not be convinced that the new online version of an existing 'Information Skills' module for 300 first-year students to familiarise themselves with library procedures and technologies was superior to the existing face-to-face module, so it was postponed.

An academic's view of memorisation can also be seen as part of his/her pedagogical stance. Cooper et al. (2002), in the improving practice section, found science academics held one of three conceptions of memorising: memorising as rote learning for reproduction, as facilitating learning - a way to progress - and as a key component of the learning process. Lecturers had opposing views on whether memorising and understanding were either unrelated processes or dynamically interwoven. So their beliefs about memorisation would feed into their orientations of either teaching-centred learning or learning-centred learning. In turn their beliefs about memorisation might or might not be shared by their students, and those disagreeing could experience disjunction.

\section{Disjunction}

Disjunction was apparent across many of the studies, and described here as a sense of becoming stuck in learning or teaching. For some staff and students there was a sense of fragmentation and uncertainty and for others it felt a little like hitting a brick wall. Disjunction has similarities with troublesome knowledge; Perkins (1999) described conceptually difficult knowledge as 'troublesome knowledge'. This is knowledge that appears, for example, counter-intuitive, alien (emanating from another culture or discourse), or incoherent (discrete aspects are unproblematic but there is no organising principle). Disjunction often feels alien and counter-intuitive. This is because it invariably feels a negative place to be, rather than as a space for growth and development. It is also similar to troublesome knowledge because until disjunction is experienced in a learning environment it is difficult to explain, particularly in terms of students feeling fragmented, which for many students can feel both constructive and destructive at the same time. 
It was noticeable that disjunction was an area addressed by few in the literature about influencing thinking and practices in higher education. It became apparent that there were trends across the studies. For example, disjunction did not necessarily always result in the displacement of identity (in the sense of a shift causing such a sense of disjunction that it resulted in a cost personally and pedagogically, and hence had a life cost), but rather in a shift in identity or role perception, so that issues and concerns were seen and heard in new and different ways. For instance, the female academics participating in the gender study by Carson (200I) did not portray themselves as being demoralised, alienated and experiencing tension between their feminine and academic selves, as some might have expected, but instead went through enabling disjunction in dealing with sexist male students and colleagues. They were entirely confident in their identities as conscientious teachers and were vociferous in derogating male academics' contributions to teaching.

The study by Bayne (2005) into the identity of learners and teachers in cyberspace found that lecturers in general were at ease with their online identity, experiencing no disjunction. Some students experienced enabling disjunction, experimenting with their online identity to differentiate it from their real self, being initially uneasy about how simple it was to portray those differences, but ultimately finding an online identity with which they were satisfied. However, most students experienced disjunction, being both initially and continually uneasy about their online identities and the ease with which it was possible to manipulate them, both by their real selves and, more importantly, by online situations.

Although disjunction occurred in many forms and in diverse ways in different disciplines, it did seem to be particularly evident in curricula where innovation had been implemented. In many of the studies there was a general sense of unmediated disjunction. For example, Ashby et al. (2006) undertook research in a nursing development initiative group consisting of health lecturers and lecturer practitioners, and set out to evaluate qualitatively how learners and teachers felt about the introduction of an enquiry-based learning (EBL) approach to education. Teachers felt more doubtful and discouraged than learners. Furthermore, several concerns were raised over the ability of EBL to establish a foothold in a curriculum more noted for a pedagogical stance on learning.

Students were also stuck in a study by Biley (1999). In this study qualitative data were collected from undergraduate student nurses $(n=45)$ who were participating in a problembased learning (PBL) programme of education. A category that was labelled 'creating tension', which consisted of two sub-categories, namely 'making the transition' and 'remembering the aims', emerged from the data. Making the transition highlighted the difficulty in moving to PBL from more traditional methods of education, whilst remembering the aims described and emphasis on the importance that students place on knowledge acquisition. Further, a study by Barrow, Lyte, and Butterworth (2002) evaluated the reiterative PBL approach in a nursing undergraduate programme using multiple methods of observation, focus group interviews and a questionnaire. Findings revealed an overall positive student experience of PBL. However, many students found PBL initially stressful due to the deliberately ambiguous nature of the scenario and the requirement upon students to direct their own learning. This was also evident in Huang (2005) and Reynolds, Saxon, and Benmore (2006). The tutor role was unclear to some students, while others found the facilitative approach empowering.

The examples of disjunction described here have been mainly from the orientation of learning-centred learning, but 'getting stuck' can occur in either orientation, in any discipline. There appear to be more instances in learning-centred learning where disjunction can be surmounted through the use of different methods, catalysts and approaches that are present within this orientation. One such aspect present in learning-centred learning was the use of learning spaces and reflection. 


\section{Learning spaces}

Learning spaces captures the idea that there are diverse forms of spaces within the life and life world of the academic where opportunities to reflect and critique their own unique learning position occur. The kinds of spaces being referred to, whilst also physical, are largely seen as mental and metaphorical. In such spaces, staff and students often recognise that their perceptions of learning, teaching, knowledge and learner identity are being challenged and realise that they have to make a decision about their own responses to such challenges. Spaces for learning offer tutors and students opportunities to examine their cultural context. The frameworks by which people live and operate may thus be challenged and transcended through the act of evaluating the world and themselves and even that very act of self-evaluation. Yet opportunities for such individual and corporate reflection can only emerge within curricula where the belief in reflection is not only espoused but also undertaken in practice. Such belief can only emerge from the premise that independent inquiry and reflection upon one's life world is worthwhile and to be valued within professions and academic institutions.

In Linder et al. (1997), physics tutors reflected on their own recent learning experiences whilst undertaking other undergraduate courses such as chemistry or geography, using a Schönian-framed coaching experience. Linder et al. created a reflective environment for tutors that led them to thinking about teaching and learning in new ways. It provided a critical framework for them to build metalearning awareness in both the content and process of learning, and helped them generate significant changes in their teaching approaches. Similarly Ashley et al. (2006) explored undergraduate and postgraduate dental students' understanding of a good learning experience by using Schön's 'reflection on learning'. Whilst teachers implemented an intuitive perspective into their practice, it was noted that a dilemma existed between the development of independent critical thinking in students, and the students' own desire for a rigidly defined course progression and structure, an emphasis on practical applications of knowledge, and learning through observation. Ashley et al. argued that their findings were of value to curriculum planners in suggesting specific ways in which students' learning could be maximised.

These two studies were unique examples that, through reflection, changed practice. It was not evident whether staff in either situation incorporated some sort of learning space for students on ongoing courses for which they were responsible, but the following example was not only used in a new course, but also maintained in an existing course module. This differing perspective was offered by Bradshaw and Moxham (2005), who used nursing students' reflective accounts describing a significant interaction with a mentally ill person for the development of a new course. Student learning enhanced subject development and the authors realised that they were not always the expert, as neither of the authors had lived with or been a mentally ill person. Understanding and using students' experiences seemed an important concern in many studies, as did the issue of diversity.

\section{Agency}

Human agency addresses the way in which people's aspirations, expectations and perceptions influence the way that they execute their roles. What is particularly important here is the structure-agency debate that introduces questions about the nature of social behaviour: whether it is ultimately predictable in terms of the creative volition of the individual, or is largely a product of socialisation, interaction and greater social structures. What is perhaps needed are 'smooth curricular spaces' which are open, flexible and contested spaces in which both learning and learners are always on the move. Movement in such curricula is not towards a given trajectory; instead, there is a sense of displacement of notions of time and place, so that curricula are delineated with and through the staff and students, they are defined by the creators of the space(s). These 
kinds of curricula are likely to be seen as risky since they prompt consideration of what counts as legitimate knowledge. In these kinds of curricula students will be encouraged to examine the underlying structures and belief systems implicit within what is being learned, in order to understand not only the disciplinary area but also its credence. Giddens' theory of structuration (Giddens 1984) is an attempt to reconcile theoretical dichotomies such as structure and agency. Giddens suggested human agency and social structure are in a relationship with each other, and it is the repetition of the acts of individual agents which reproduces the structure. This means that social structure such as traditions, institutions, moral codes and established ways of doing things can be changed when students begin to ignore them, replace them, or reproduce them differently. Thus perhaps what needs to be explored further in terms of ways of thinking, and practices related to teaching and learning, are the three types of structures (Giddens 1984) in social systems, those of:

- Signification: produces meaning through organised webs of language and even the language of webs.

- Legitimation: produces a moral order via naturalisation in societal norms, values and standards, but which might be challenged through knowledges created in and through learning and teaching practices.

- Domination: produces (and is an exercise of) power, originating from the control of resources, which can be transgressed though produsage. '

This was clearly shown in Land (2004), who demonstrated that educational development can be directed towards supporting the academic as an individual to promote personal well-being and growth. In the study by Trowler and Cooper (2002), a tutor with only months of teaching experience challenged the programme as inappropriate. The fact that his inexperience as a teacher was highlighted suggests that his intervention was regarded as inappropriate for his length of tenure; his prior experience in industry was disregarded, even though it may have been highly relevant to his judgement of the appropriateness of the course. Since a core aim of higher education is the production of people with skills appropriate to the workplace, the dismissal of an individual's industrial experience suggests that the educational institution lends greater weight to teaching experience than the requirements of future employers. In contrast, a teacher of nine years' tenure deemed judgement of his particular failure on a teaching and learning course to be inappropriate, due to his accumulated experience in teaching.

In contrast, Land (2004) shows that an acceptance of needs at an individual level had led to the adoption of a flexible organisation that responded to personal agency. On an individual level people define their own position and act accordingly. The study by Land (2004) illustrated how teachers unwilling to take on managerial roles appeared to perform as required but were waiting to resume their own agendas, thus revealing the ingrained nature of pre-learned repertoires and personal agency. Further, the study by Lucas (1998) showed how a lack of engagement of students with the subject area, and a lack of personal relevance in accounting, is due to the agency of the individual student. Many students found the subject dull, only relevant in the future and a subject that had to be passed at examination. This personal agency is however misread by lecturers as confusion and insufficient work input:

Don't work hard enough, don't read around the subject, do the work mechanically, don't know enough about business, and have confusion about financial information.

In contrast creative writers showed no interest in discussing their ideas:

I'm sure that most people who write, who have any interest in writing, cannot handle the idea of sharing, sharing their ideas. If they do it's very superficial. (Light 2002, 268) 
Similarly, cultural aspects of human agency are revealed in a study by Huang (2005) where students found debate with lecturers difficult:

I am happy to discuss problems with my team mates. However, I did find that I had a huge difficulty when arguing with my lecturers, especially when they were wrong about some issues. I think this is a problem that most Chinese students in the UK would have. (4I)

The concept that the transfer of information between communities is a simple mechanistic process falls short of reality, since it regards communities as uniform assemblages linked by a bureaucratic structure and has little regard for the complex interplay invoked by human agency. By responding to the role of agency at an individual level, an organisation will be imbued with a degree of flexibility that will enable adaptation to the needs of the communities involved.

\section{Notions of improvement}

Notions of improvement captured the idea that across the themes of practice, transfer and community there were particular beliefs about how improvement should be undertaken. Furthermore, there was often, but not always, a sense that top-down improvement was inadvisable. Notions of improvement appeared to span four perspectives:

(I) Improvement that was imposed by the institution would not be valued - yet in a number of studies this was not the case.

(2) Improvement was seen as something imposed via government agenda with little organisation and planning along with mixed messages, and therefore would not work. Yet this approach also worked to some degree, see for example Burke $(2003,2006)$, in the move of nursing into higher education from its past health service position.

(3) Bottom-up and top-down approach would work most effectively. This proved to be the case in many studies, for example Wilkie (2002). However there were instances where this was not the case. For example, Pollock and Cornford (2002) have shown wellfunded innovation stalling through lack of ongoing leadership and support.

(4) Bottom-up improvement was expected to be the best approach, but there were several cases where in fact this approach had relatively little impact. For example Souleles (2005) detailed the issues for staff implementing e-learning innovation with adequate practical support, but there was a lack of pedagogical inspiration about how best to use the new technology in order to maximise students' learning opportunities. The study revealed one academic paying lip-service to the innovation by merely placing their lecture notes on Blackboard, while others, although recognising the infinite possibilities of e-learning, lacked guidance in how to proceed, and were reduced to a trial and error approach in order to discover which processes and activities resulted in enriched learning.

The analogy of crossing the chasm (Moore 1999, following Rogers 1962) was a useful way of engaging with many of the issues related to notions of improvement. Moore's work relates to the development and adoption of technology within companies. He argued that there is a chasm between two distinct marketplaces: an early market that tends to dominated by those keen to take it on board (early adopters), along with insiders who quickly see the benefit of the new development. The second marketplace is characterised by a range of people who ultimately want the benefits of the new technology but are slower to take it up and more cynical about its possibilities. What tends to occur is the emergence of a chasm between those in the early market and those in the later mainstream market. Crossing this chasm is an important focus for those involved in any innovation, since it highlights not only challenges inherent in the adoption of new technology but also with any innovation that affects people's lives and ways of seeing the world. 


\section{Communities of interest}

There has been much discussion on the notion of community, and in particular the idea of communities of practice (Lave and Wenger 1991). The concept of a community of practice refers to the process of social learning that occurs when people who have a common interest in some subject or problem collaborate over an extended period to share ideas, find solutions, and build innovations. However, it would seem the term 'Community of Interest' would fit better with those studies located in the communities section, since it reflects the idea of a group of people who share a common interest or passion. The people who exchange ideas and thoughts and engagement in such a community of interest often find it very compelling. For some academics it might seem that in a number of the higher education communities there is an evangelistic strand that seeks to convert the souls who are perceived to belong to the wider, more liberal end of the church, while for others there is little real rivalry across the spectrum. The idea of 'community' from the stance of rhetorical criticism offers an opportunity to explore both the medium and the message of the approach. The interpretation of meaning within the communities can help us to understand the way in which dramatic narratives are projected, to see the characters, plots and storylines that are at play globally, and thus be able to locate the hallmarks of a rhetorical community. Thus the kinds of hallmarks that might be seen are:

(I) Ideological and procedural assumptions such as: community practices will be carried out in particular ways; certain plots and storylines are more acceptable than others.

(2) There are codes, slogans and key words that are accepted by the community. These are understood by those in the community and promulgated by those in leading roles, such as consultants, authors of texts and keynote speakers.

The hallmarks of communities of interest were seen across many studies in this review, particularly in relation to academic practice (Land 2004) and enquiry-based learning (SavinBaden 2000; Wilkie 2004) as well the e-learning communities.

\section{Further research and recommendations}

Future attempts at meta-ethnography could draw upon what has been undertaken here, extending and challenging our work. Different criteria for inclusion and exclusion and different methods of evaluating research based upon different philosophical stances in relation to research can only add to the existing body of research, directing and developing new ways to know and understand. However, further research needs to be undertaken in order to explore the following areas:

(I) There is a need to develop commonly understood discourses about teaching and learning as a pre-requisite to being able to make teaching and learning regimes explicit and challenging them openly. Further, the changing nature of the university experience, combined with the changing nature of the student body, produced significant shifts in the experience of higher education that are not fully visible or understood in all their implications. This culture shift has affected institutional ability to respond to diverse needs and expectations and this requires further research.

(2) There remains relatively little understanding of the impact of disciplinary differences across teaching and learning research and practices. This bears further research and there needs to be further exploration into the impact of diverse teaching methods on students' experiences. Furthermore, the impact of academic identities and in particular staff pedagogical stances in ways of thinking and practising requires still further research.

(3) The professionalisation of teaching remains problematic and further research and changes in funding and university practices are required to engage with this. 
(4) E-learning pedagogy is largely missing from the literature and needs to be developed and researched. There is a lack of availability and/or opportunity for appropriate professional development in e-learning, which is an institutional issue that needs to be addressed,

(5) Research into learning spaces (that reaches beyond that of design for learning) requires further study.

\section{Conclusion}

Interpretive meta-ethnography such as this affords an opportunity not only to compare studies and the themes identified by the authors, but also to construct an (always contestable) interpretation. However, the difficulty with this approach is that there is a tendency to privilege similarity (and sometimes difference) because the process of sense making across studies tends to focus on ordering and cohesion rather than exploring conflicting data sets and contestable positions.

This review began by trying to find key themes in the literature on teaching and learning thinking and practices by examining areas of influence and mapping ideas about the themes of practice, transfer and communities in higher education or related contexts. What has been mapped are the varieties, versatility and vagaries of influencing thinking and practice about teaching and learning in higher education. Whilst this review presents research and practice, disciplinary differences and similarities, it also shows that issues of pedagogical stance, disjunction, learning spaces, agency, notions of improvement and communities of interest all help to locate overarching themes and hidden subtexts that are strong influences on areas of practice, transfer and community. Nevertheless, these are areas that are sometimes ignored, marginalised or dislocated from the central arguments about teaching and learning thinking and practices in higher education. Moreover, although there is a significant body of work that can inform practice, transfer and communities, in the main this is underused in the processes of design and decision making to implement innovation and change or guide communities in ways of thinking and practising.

\section{Notes}

I. Bruns (2007) has suggested that we are now in the realms of 'produsage', characterised by communitybased production, fluid roles, unfinished artefacts and common property.

\section{Notes on contributors}

Maggi Savin-Baden is Professor of Higher Education Research at Coventry University and Director of the Learning Innovation Group.

Lorraine McFarland is a Senior Researcher and teaching fellow at Coventry University.

John Savin-Baden is a part-time educational researcher and a full-time domestic administrator.

\section{References}

Ashby, J., V. Hubbert, L. Cotrel-Gibbons, K. Cox, J. Digan, K. Lewis, G. Langmack, M. Matiti, D. McCormick, L. Roberts, and D. Taylor et al. 2006. The enquiry-based learning experience: An evaluation project. Nurse Education in Practice 6: 22-30.

Barnett, R. 1990. The idea of higher education. Buckingham, UK: Open University Press/Society for Research into Higher Education.

. 1994. The limits of competence. Buckingham, UK: Open University Press/ Society for Research into Higher Education. 
1997. Higher education: A critical business. Buckingham, UK: Open University Press/Society for Research into Higher Education.

. 2000a. Realizing the university in an age of supercomplexity. Buckingham, UK: Open University Press/Society for Research into Higher Education.

2000b. Supercomplexity and the curriculum. Studies in Higher Education 25, no. 3: 254-65.

Barrow, E., G. Lyte, and T. Butterworth. 2002. An evaluation of problem-based learning in a nursing theory and practice module. Nurse Education in Practice 2: 55-62.

Bauman, Z. 2000. Liquid modernity. Cambridge: Polity Press.

Bayne, S. 2005. Deceit, desire and control: The identities of learners and teachers in cyberspace. In Education in cyberspace, ed. R. Land and S. Bayne, 26-4I. London: Routledge.

Becher, T. 1989. Academic tribes and territories: Intellectual enquiry and the cultures of disciplines. Buckingham, UK: Society for Research into Higher Education and Open University Press.

Becher, T., and P.R. Trowler. 200I. Academic tribes and territories, 2nd ed. Buckingham, UK: Society for Research into Higher Education and Open University Press.

Biley, F.C. 1999. Creating tension: Undergraduate student nurses' responses to a problem based learning curriculum. Nurse Education Today 19: 586-91.

Bradshaw, B., and L. Moxham. 2005. The psychiatric consumer: The use of student stories to inform course development. Studies in Learning, Evaluation Innovation and Development 2, no. 2: 39-48.

Bruns, A. 2007. Beyond difference: Reconfiguring education for the user-led age. Paper presented at Ideas in Cyberspace Education, 2I-23 March, at Loch Lomond, Scotland, UK. http:// www.education.ed.ac.uk/ice3/papers/bruns.html.

Burke, L.M. 2003. Integration into higher education: Key implementers' views on why nurse education moved into higher education. Journal of Advanced Nursing 42, no. 4: 382-9.

. 2006. The process of integration of schools of nursing into higher education. Nurse Education Today 26, no.1: 63-70.

Carson, L. 200I. Gender relations in higher education: Exploring lecturers' perceptions of student evaluations of teaching. Research Papers in Education 16: 337-58.

Cooper, I., M. Frommer, S. Gordon, and J. Nicholas. 2002. University teachers' conceptions of memorising in learning science. Higher Education Research \& Development 2I, no. 3: 305-2I.

Freire, P. 1972. Pedagogy of the oppressed. London: Penguin Books.

. 1974. Education: The practice of freedom. London: Writers and Readers Co-operative.

Giddens, Anthony. 1984. The constitution of society. Outline of the theory of structuration. Cambridge: Polity Press.

hooks, b. 1994. Teaching to transgress. London: Routledge.

Huang, R. 2005. Chinese international students' perceptions of the problem-based learning experience. Journal of Hospitality, Leisure, Sport and Tourism Education 42: 38-43.

Jenkins, A., and R. Zetter. 2003. Linking teaching and research in departments. York, UK: LTSN Generic Centre.

Land, R. 2004. Educational development, discourse, identity and practice. Maidenhead, UK: Society for Research into Higher Education/Open University Press.

Lave, J., and E. Wenger. 199I. Situated learning: Legitimate peripheral participation. Cambridge: Cambridge University Press.

Light, G. 2002. From the personal to the public: Conceptions of creative writing in higher education. Journal of Higher Education 43, no. 2: 257-76.

Linder, C., C. Leonard-McIntyre, D. Marshall, and R.M. Nchodu. 1997. Physics tutors' metalearning development through an extension of Schön's reflective practice. International Journal of Science Education 19, no.7: 821-33.

Lucas, U. 1998. Accounting for the world and the world of accounting: Phenomenographic research in accounting education. Higher Education Close Up. University of Central Lancashire, Preston. http://brs. leeds.ac.uk/ beiwww/BEIA/hecu98.htm

Meyer, J.H.F., and R. Land. 2003. Threshold concepts and troublesome knowledge: Linkages to ways of thinking and practising within the disciplines. In Improving student learning: Theory and practice -10 years on, ed. C. Rust, 4I2-24. Proceedings of the 10th Improving Student Learning Conference. Oxford: Oxford Centre for Learning and Staff Development.

- 2005. Threshold concepts and troublesome knowledge (2): Epistemological considerations and a conceptual framework for teaching and learning. Higher Education 49, no. 3: 373-88.

Moore, G.A. 1999. Crossing the chasm, 2nd ed. Oxford: Capstone Publishing.

Noblit, G.W., and R.D. Hare. 1988. Meta-ethnography: Synthesizing qualitative studies. Newbury Park, CA: Sage. 
Perkins, D. 1999. The many faces of constructivism. Educational Leadership 57, no. 3: 6-II.

Pollock, N., and J. Cornford. 2002. The theory and practice of the virtual university: Working through the work of making work mobile. Minerva 40: 359-73.

Pratt, D.D., and associates. 1998. Five perspectives on teaching in adult and higher education. Malabar, FL: Krieger, Publishers.

Prosser, M., and K. Trigwell. 1999. Understanding learning and teaching: The experience in higher education. Buckingham, UK: Open University Press.

Reynolds, R., D. Saxon, and G. Benmore. 2006. Impact on the student experience of extending problembased and enquiry-based learning. Industry and Higher Education 20: 359-70.

Rogers, E.M. 1962. Diffusion of innovations. New York: The Free Press.

Samuelowicz, K., and J.D. Bain. 200I. Revisiting academics' beliefs about teaching and learning. Higher Education 4I, no. 3: 299-325, 327.

Savin-Baden, M. 2000. Problem-based learning in higher education: Untold stories. Buckingham, UK: Open University Press/Society for Research into Higher Education.

Savin-Baden, M., and C. Major. 2007. Fractured pedagogies and shattered worlds: Using interpretative meta ethnography to explore the relationship between innovative approaches to learning and the influence on faculty understanding of teaching. Higher Education 54, no. 6: 833-52.

Souleles, N. 2005. Staff use of e-learning and graduate competencies for the knowledge economy: A study of the misalignment between rhetoric and practice. E-learning 2, no. 3: 224-37.

Trowler, P., and A. Cooper. 2002. Teaching and learning regimes: Implicit theories and recurrent practices in the enhancement of teaching and learning through educational development programmes. Higher Education Research \& Development 21, no. 3: 22I-40.

Wilkie, K. 2002. Action, attitudes and attributes: Developing facilitation skills for problem-based learning. Unpublished PhD thesis, Coventry Univ.

. 2004. Becoming facilitative: Shifts in lecturers' approaches to facilitating problem-based learning. In Challenging research in problem-based learning, ed. M. Savin-Baden and K. Wilkie. Maidenhead, UK: McGraw-Hill. 